Çukurova Üniversitesi Mühendislik Mimarlık Fakültesi Dergisi, 31(2), ss. 159-166, Aralık 2016

Çukurova University Journal of the Faculty of Engineering and Architecture, 31(2), pp. 159-166, December 2016

\title{
Çamlıbel (Tokat) Diyabazlarının Fiziko-Mekanik Özelliklerinin Araştırılması
}

\author{
Esma KAHRAMAN"1 ${ }^{*}$ Ahmet Mahmut KILIÇ ${ }^{1}$ \\ ${ }^{I}$ Çukurova Üniversitesi, Mühendislik Mimarlık Fakültesi, Maden Mühendisliği Bölümü, Adana
}

Geliş Tarihi: 02.06.2016

Kabul Tarihi: 23.11 .2016

$\ddot{\mathbf{O} z}$

Diyabaz, yüksek dayanım özelliğinden dolayı inşaat sektöründe yaygın olarak kullanılmaktadır. Bu çalışmada; Çamlıbel (Tokat) diyabazlarının bazı fiziko-mekanik özellikleri belirlenmiştir. Deneyler TS 699'a göre yapılmıştır. Deneysel çalışmalarda; Birim hacim ağırlık, su emme, porozite, eğilme dayanımı, don sonrası eğilme dayanımı, böhme aşınma dayanımı, tek eksenli basınç dayanımı ve sertlik değerleri bulunmuştur. Bütün bunların yanı sıra; kimyasal, petrografik ve mineralojik özellikleri de belirlenmiştir. Deneyler sonucunda diyabazın sınıflandırılması yapılmış ve ülkemizdeki standartlara uygun olup olmadıkları belirlenmiştir. Deney ve incelemeler sonucunda elde edilen veriler Çamlıbel (Tokat) diyabazlarının TSE Standartlarına göre yapılarda döşemede iç ve dış kaplamada kullanılabilir olduğunu göstermiştir.

Anahtar Kelimeler: Diyabaz, Fiziksel özellikler, Mekanik özellikler, TSE standartları

\section{Investigation of Pyhsico-Mechanical Properties of Çamlıbel (Tokat) Diabases}

\begin{abstract}
Diabase is widely used in construction industry because of highly strength properties. This study aims at determining the some physical and mechanical properties of Çamlıbel (Tokat) diabase. Experimental studies were determined according to TS 699. In this study, appearance, unit volume weight, water absorption ratio, hardness, porosity, flexural strength, böhme abrasion resistance, bending strength and bending strength value after frost were found. In addition to the chemical, petrographic and mineralogical characteristics were determined. According to the results of the experimental studies, the diabase samples have been classified and investigated if they are suitable to standards in country. In result of obtained data indicated the Çamlıbel of diabases usable in structure, floor, interior trim and shell by TSE standard.
\end{abstract}

Keywords: Diabase, Physical properties, Mechanical properties, TSE standards

\footnotetext{
*Sorumlu yazar (Corresponding author): Esma KAHRAMAN, ekahraman@cu.edu.tr
} 


\section{GİRIŞ}

Doğal taşlar insanlığın var oluşundan beri pek çok amaç için kullanılmaktadır. Kullanım alanlarının en başında ise inşaat sektörü gelmektedir. Ülkemizde gelişen inşaat sektörünün talepleri doğal taş üretiminin hız kazanmasına yol açmıştır.

Türkiye'de doğal taş olarak kullanılabilen çeşitli renk ve desende kristalin kalker (mermer), kalker, traverten oluşumlu kalker (oniks), konglomera, breş ve magmatik kökenli kayaçlar (granit, siyenit, diyabaz, diyorit, serpantin, vb.) bulunmaktadır. Dünya pazarlarında beğeni kazanabilecek nitelikte doğal taş çeşidine sahip olan Türkiye'de, rezervler Anadolu ve Trakya boyunca geniş bir bölgeye yayılmıştır. Rezervlerin bölgelere göre dağılımı, Ege Bölgesi \%32, Marmara \%26, İç Anadolu \%11, Doğu Anadolu Güneydoğu Anadolu, Karadeniz ve Akdeniz Bölgesi \%31 şeklindedir [1].

Sektörde yaklaşık 1.500 adet doğal taş ocağ1, fabrika ölçeğinde faaliyet gösteren 2.000 kadar tesis, orta ve küçük ölçekli 9.000 atölye faaliyet göstermektedir. İstihdam edilen kişi sayısı 300.000 civarındadır. Üretimin en fazla olduğu iller; Balıkesir, Afyon, Bilecik, Denizli ve Muğla'dır. $\mathrm{Bu}$ bölgelerdeki üretim, tüm üretimin $\% 65$ 'ini oluşturmaktadır. Ekonomik mermer yataklarının bulunduğu diğer iller ise; Bursa, Kırşehir, Çankırı, Çorum, Kastamonu, Niğde, Kayseri, Artvin, Bitlis, Erzincan, Bayburt, Sivas, Tokat, Denizli, Kütahya, Eskişehir, Diyarbakır, Elazı ğ, Çanakkale, Konya, İstanbul ve Manisa'dır. Ülkemizde 80'nin üzerinde değişik yapıda, 120'nin üzerinde değişik renk ve desende mermer ve doğal taş rezervi belirlenmiştir.

İşlenmesi güç olmasına rağmen diyabazın doğal taş olarak kullanılması oldukça yaygındır. Bunun nedenleri [2];

- Renginin güzel olması,

- Dayanımının yüksek olması,

- Cila tutma özelliğinin yüksek olması,

- Cilasını uzun süre koruyabilmesi,

- Su emme oranının düşük olmasıdır

Diyabaz konutlarda gerek iç gerekse dış mekan uygulamaları olarak yaygın bir şekilde kullanılmaktadır. Özelikle cephe, zemin, kolonsütun, merdiven kaplamaları, park, bahçe, meydan, yürüyüş yolları, trafiğe kapatılmış kent içi yol, üstalt geçit, köprü kaplamaları ile duvar ve havuz kaplamalarında kullanılır [3]. Diyabaz taşının atıkları; parke taşı, karayolları üst yapı kaplamasında micır, demiryollarında raylar arasına serilen sikılama malzemesi (balast), beton üretiminde kullanılan granüler malzeme, seramik sanayinde sırlama yapımı ham maddesi, yap1 kimyasalları sanayinde mikronize kum ve izolasyon sanayinde kaya yününün hammaddesi olarak değerlendirilebilmektedir.

Bu çalışmada; Çamlıbel (Tokat) diyabazının bazı mekanik ve fiziksel özellikleri incelenmiştir. Ayrıca kimyasal, mineralojik ve petrografik açıdan da incelemeler yapılmıştır. Deneylerden elde edilen bulgular TSE standartları ile ilişkilendirilerek Çamlıbel (Tokat) diyabazlarının kullanım alanları belirlenmiştir. Şekil 1'de diyabazın makroskobik görüntüsü verilmiştir.

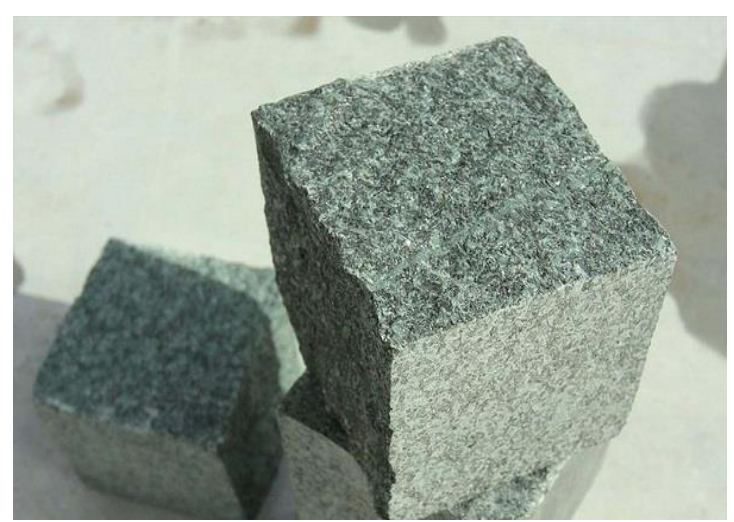

Şekil 1. Çamlıbel diyabazı görüntüsü

\section{2. ÇALIŞMA ALANI}

\subsection{Coğrafi Konum}

Çalışma alanı Tokat İli Merkez İlçesi sınırları içinde bulunan Çamlıbel mevkiinde Çatalkaya Köyü'nün $500 \mathrm{~m}$ güneyinde, yer almaktadır. Ulaşım D850 ve D 190 karayolu üzerinden sağlanmaktadır. Şekil 2'de çalışma sahası üretim basamaklarının genel görüntüsü verilmektedir. 


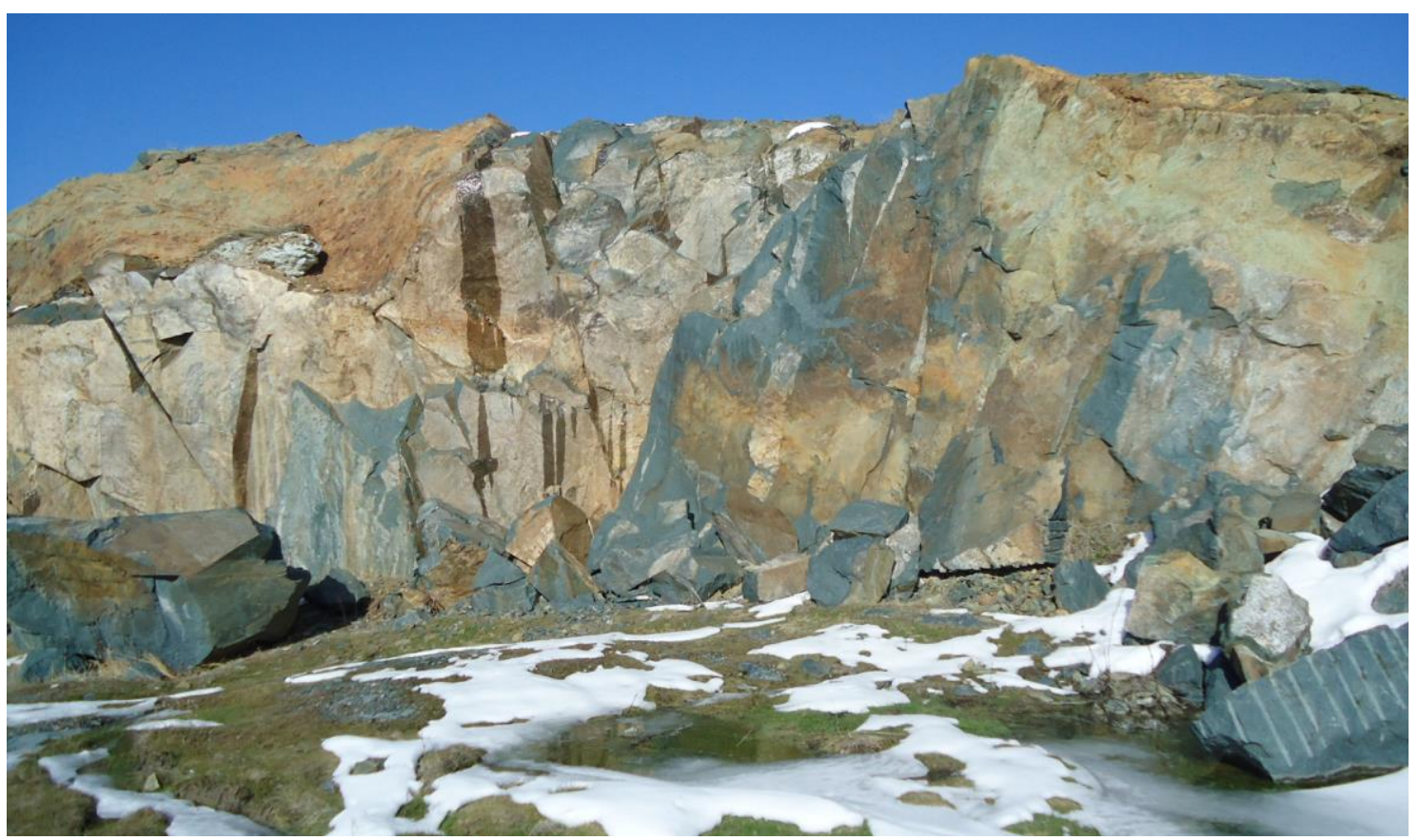

Şekil 2. Çalışma sahası üretim aynasının genel görüntüsü

\subsection{Bölgesel Jeoloji}

Çalışma bölgesinin büyük bir kısmı ofiyolitik seri ile kaplıdır. Seride alttan üste doğru serpantinitler ve diyabazlar şeklinde genel bir stratigrafik sıralanma saptanmıştır. Bölgede bulunan seride ofiyolitik serisindeki sedimanter kayaçların genellikle küçük ve dağınık zuhurlar halinde ofiyolitlerin üzerinde, yer yer de içlerinde sokulu olarak bulunuşları, seriye ofiyolitik melanj görünümü kazandırmaktadır [4].

Ultramafiklerin esasını ve temelini serpantinitler oluşturmakta ve arazide kolayca izlenebilmektedir. Vadiler boyunca diyabaz örtüsü altından serpantinit mostraları gözlenmiştir. Kurtsekisi Tepe bölgesinde, serpantinitler üzerinde aşınma ile ortaya çıkmış diyabaz kalıntılarına rastlanmaktadır. Ofiyolitik serinin güneyindeki sinırlar ise tektoniktir. Serpantinitler bölgede ortalama $400 \mathrm{~m}$ kadar bir kalınlığa ulaşmaktadır. Kayaç çoğunlukla masif görünümlü, yer yer kırıklı, fazla tektonize olan kısımlarda ezikli ve kısmen şistî yapıya sahiptir. Serpantinleşme derecesi genellikle yüksektir. Bu oranın \%15 gibi düşük olduğu peridotitlere, Çamlıbel geçidinin 1 km kuzeydoğusunda rastlanmıştır. Mikroskobik inceleme sonucu peridotitlerin bu kisımlarda lerzolit özelliği taşıdığı anlaşılmıştır. Serpantinitler içinde serpantin mineralleriyle olivin ve piroksenden başka klorit, manyetit, kromit, uvarovit ve grossüler mineralleri saptanmıştır. Kloritleşme arazinin kuzeydoğu kesiminde, uvarovite Balıbey'in $2 \mathrm{~km}$ kadar güneyinde ve Çamlıbel'in $3 \mathrm{~km}$ kadar kuzeybatısında rastlanmıştır [4].

Bölgede bulunan başka bir ultramafik kayaç türü de piroksenittir. Ancak piroksenite sadece Pamukpınar'ın $5 \mathrm{~km}$ kuzeyinde, serpantinitler içinde iki küçük damar halinde rastlanmıştır. Piroksenit hipersten, diyopsit, uralit ve kromit mineralleri kapsar. Hipersten içinde prizmatik dilinime paralel çok ince klinopiroksen levhacıkları olduğu gibi, kısmen uzunca, kısmen şekilsiz klinopiroksen artıkları da görülmüştür [4].

Ultramafiklerin üzerindeki bazik volkanit örtüsünün bölgemizdeki görünür kalınlığı 150-300 $\mathrm{m}$ arasında değişmektedir. $\mathrm{Bu}$ volkanitlerin 
diyabaz tanımına uygun kayaçlar olduğu, özellikle mikroskobik incelemeler sonucunda ortaya çıkmaktadır. Ofiyolitik seri içinde yer alan bazaltik-andezitik bileşimli bu denizaltı volkanitlerinin sonradan kloritleşme ve kısmen de uralitleşme şeklindeki yeşillenmeleri karakteristik özelliklerindendir. Bölgede serpantinitler içindeki rodenjitler hariç tutulursa, diyabaz damarlarına, ya da diyabazların çıkış kanalı olarak yorumlanabilecek yapılara rastlanmamıştır. Yastık lavlara ise orijinal çalışmanın tamamlanmasından sonra, yol yapımı sırasında açılan mostralarda, Büyüktor Kurtsekisi tepeleri arasında rastlanmıştır. Diyabazlar genellikle ince taneli, değişik tonlarda yeşil renklidir. Kahverengi veya koyu gri kısımları da bulunmaktadır. Alaca köyü civarında diyabazlar yanında tüf ve aglomeralar da yer almaktadır [4].

\section{YÖNTEM}

Tokat Çamlıbel bölgesinden alınan diyabazlarının bazı hammadde özelliklerini belirlemek amacı ile numuneler öncelikle standarda uygun olarak hazırlanmıştır. Hazırlanan numunelere fiziksel deneyler, mekanik deneyler, kimyasal deneyler ve petrografik analizler uygulanmıştır.

- Diyabaz numunesinin kimyasal içeriği yarı kantitatif Panalytical marka X-Ray Fluoresence cihazı ile yapılmıştır.

- Petrografik analiz; çıplak göz, lup ve hazırlanmış ince kesitler ile yapılmıştır. İnce kesitler Olympus $\mathrm{BH}-2$ marka polarizan mikroskop ile incelenmiştir.

- Mekanik ve fiziksel özellikler TS 5762 [6] standardına uygun olarak yapılmıştır.

\section{ARAŞTIRMA BULGULARI}

\subsection{Fiziksel Özellikler}

Deneyler sonucunda diyabazın fiziksel özelliklerinden özgül ağırlık, birim hacim ağırlık, porozite oranı ve doluluk oranları belirlenmiştir. Özgül ağırlık 2,91 $\mathrm{g} / \mathrm{cm}^{3}$ olarak bulunmuştur. Doğal yapı taşlarının yapılarda kullanılabilmesi için özgül ağırlık değerinin $2,55 \mathrm{~g} / \mathrm{cm}^{3}$ 'den küçük olmaması gerekmektedir [5]. Her bir deney için beşer tane örnek kullanılmış ve bulunan değerlerin ortalaması alınmıştır. Çizelge 1'de deney sonucunda belirlenen fiziksel özelliklerin ortalama değerleri verilmiştir.

Numunenin kuru birim hacim ağırlığı ve doygun birim hacim ağırlığı olmak üzere iki farklı birim hacim ağırlığı belirlenmiştir. Deney sonucunda Çamlıbel diyabazlarının kuru birim hacim ağırlığı $2,818 \mathrm{~g} / \mathrm{cm}^{3}$ ve doygun birim hacim ağırlığ $2,825 \mathrm{~g} / \mathrm{cm}^{3}$ bulunmuştur. TS 5762 [6]'e göre yapı ve kaplama olarak kullanılabilmesi için örneğin birim hacim ağırlığının en az $2,55 \mathrm{~g} / \mathrm{cm}^{3}$ olması gerekmektedir.

Çizelge 1. Çamlıbel diyabazının fiziksel özellikleri

\begin{tabular}{|c|c|c|}
\hline Fiziksel Özellikler & $\begin{array}{l}\text { Bulunan } \\
\text { Değer }\end{array}$ & $\begin{array}{c}\text { TS } 5762 \\
\text { Sinır } \\
\text { Değer }\end{array}$ \\
\hline $\begin{array}{l}\text { Kuru Birim Hacim } \\
\text { Ağırlık }\left(\mathrm{g} / \mathrm{cm}^{3}\right)\end{array}$ & $2,818 \pm 0,01$ & \multirow{2}{*}{$\begin{array}{c}\text { Kaplama } \\
\geq 2,55\end{array}$} \\
\hline $\begin{array}{c}\text { Doygun Birim } \\
\text { Hacim Ağırlık } \\
\left(\mathrm{g} / \mathrm{cm}^{3}\right)\end{array}$ & $2,825 \pm 0,01$ & \\
\hline $\begin{array}{c}\text { Ağırlıkça Su Emme } \\
(\%)\end{array}$ & $0,21 \pm 0,05$ & $\begin{array}{l}\text { Kaplama } \\
\leq 0,75\end{array}$ \\
\hline $\begin{array}{l}\text { Porozite } \\
\qquad \%)\end{array}$ & $1,89 \pm 0,08$ & $\begin{array}{c}\text { Kaplama } \\
\leq 2\end{array}$ \\
\hline Doluluk Oranı (\%) & $99,11 \pm 0,08$ & $\begin{array}{c}\text { Kaplama } \\
\geq 2,55\end{array}$ \\
\hline
\end{tabular}

Doğal yapı taşlarında numunenin su emmesinin düşük olması istenir. TS 5762 [6]'e göre diyabazların yapı ve kaplama taşı olarak kullanılması için su emme miktarının en fazla 0,75 olması gerekmektedir. 
Doğal yapı taşlarında porozite önemli bir olgudur. Porozite oranının artması numunenin taşın kalitesini düşürecektir. Porozitenin fazla olması sıv1 ve gaz geçirgenliğini arttırmaktadır. İç yüzeylerinde sıvı ve gazın tutulmasını da sağlamaktadır [7].

TS 1496 [5] ve TS 5762'e [6] göre kaplama olarak kullanılan doğal taşların porozitesinin \%2'den fazla olmaması, buna bağlı olarak doluluk oranının ise \%98'den az olmaması istenmektedir. Tarhan tarafından yapılan kayaçların poroziteye göre sınıflaması Çizelge 2'de verilmektedir [8]. Çizelgeye göre Çamlıbel Diyabazı \%1,89 değeri ile "az boşluklu" kaya sınıfındadır.

Yapılan fiziksel deneylerde diyabaz örneklerimizin fiziksel özelliklerinin kaplama ve yapı taşı olarak kullanılmasının uygun olduğu gözlenmiştir. Bulunan tüm değerlerin ilgili standartlarda verilen sınır değerleri sağladığı açıkça görülmektedir.
Çizelge 2. Kayaların porozite sınıflaması [8]

\begin{tabular}{|c|c|}
\hline Kaya Sınıfı & Porozite \% \\
\hline Çok Kompakt & $<1$ \\
\hline Az Boşluklu & $1-2,5$ \\
\hline Orta Boşluklu & $2,5-5$ \\
\hline Oldukça Boşluklu & $5-10$ \\
\hline Çok Boşluklu & $10-15$ \\
\hline Çok Fazla Boşluklu & $>20$ \\
\hline
\end{tabular}

\subsection{Petrografik ve Mineralojik Analiz}

Magmatik derinlik kayacıdır. Ana hakim mineraller plajiyoklas, piroksen ve opak minerallerdir ve doloritleşme gözlenmiştir (Şekil 3, 4).

Piroksen: ileri derecede alterasyona uğramıştır. Özellikle krolitleşme görülmektedir.

Opak Mineraller: Kayacın içerisinde özşekilsiz demir opakları şeklinde bulunmaktadır.

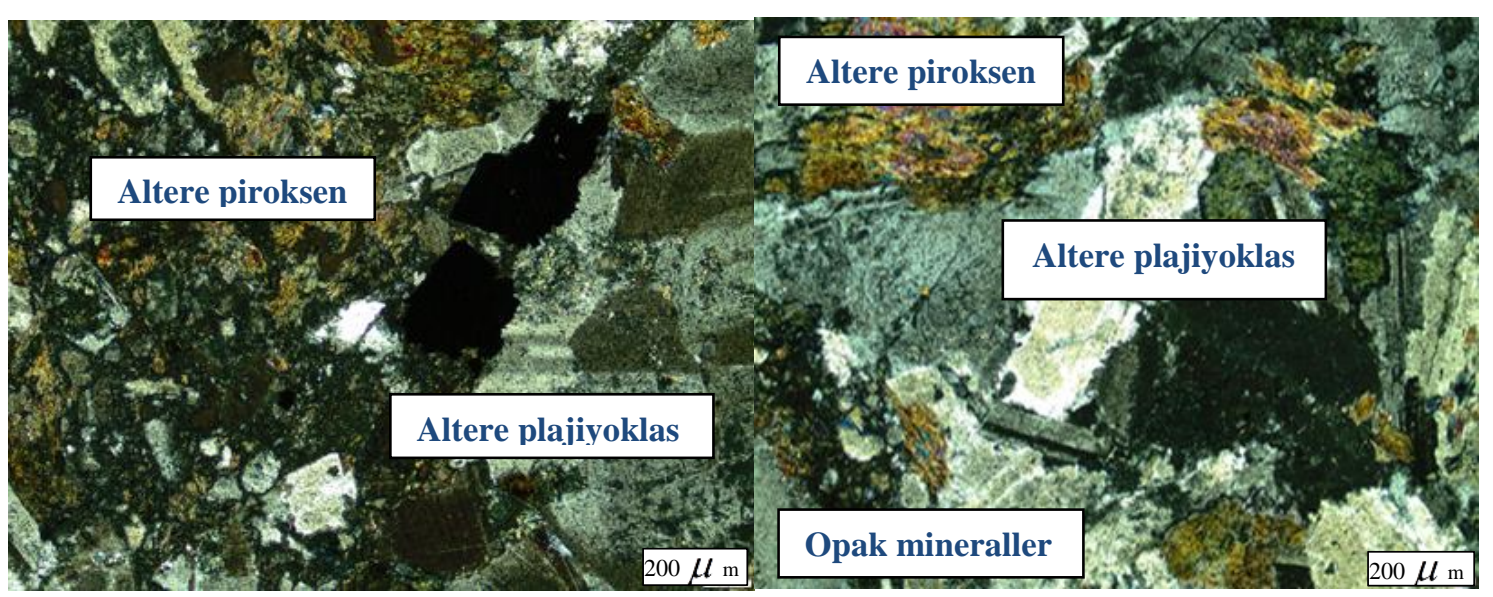

Şekil 3. Çamlıbel diyabazlarına ait altere olmuş plajiyoklas, piroksen ve opak mineraller (Çift nikol)

Feldispat: İri mafik mineraller şeklindedir. Çoğunluk olarak polisentetik ikizlenme göstermektedir. Çoğu öz şekilsiz ve yarı öz şekillidir. Tamamına yakınında serizitleşme mevcuttur. Yani alterasyona uğramıştır.
Kayaç porfiroblast dokulu olup, bazik bileşimlidir. Minerallerinde gözlenen dönüşüm kayacın kısmen doloritleştiğini ifade etmektedir. Kayaç yapı ve mineral bileşimi olarak diyabaz bileşimindedir. 


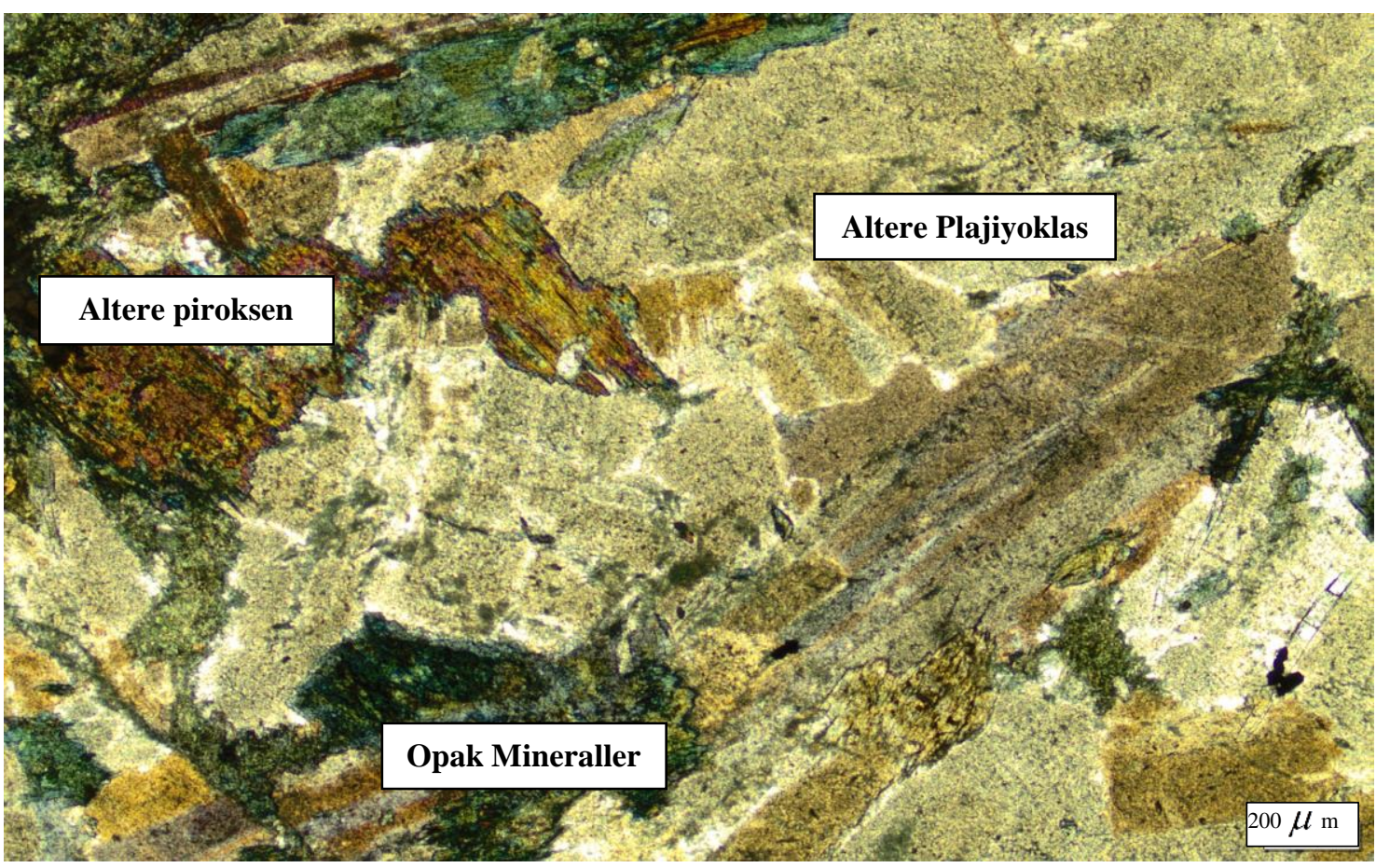

Şekil 4. Örneğe ait altere olmuş plajiyoklas ve piroksenler (Tek nikol)

Diyabaz, esas olarak genellikle labrodordan ibaret bazik plajyoklas ile genellikle, ojitten ibaret bazik monoklinik piroksenden meydana gelen, tali olarak da apatit, kuvars, oligoklas, andeniz, magnetit, ilmenit, ortoklas, hornblend, biyotit ve olivin mineralleri ihtiva eden belirgin ofitik dokuya sahip bazaltik bir taştır. Diyabazların içeriğine göre siniflaması [10];

- Olivin Diyabaz; bünyesindeki olivin miktarı $\% 2$ 'den fazla olan diyabazdir.

- Kuvars Diyabaz; bünyesindeki kuvars miktarı $\% 2$ 'den fazla olan diyabazdır.

- Piroksenli Diyabaz; bünyesinde ojite ilaveten, ojitten daha fazla oranda piroksenli/hipersten içeren diyabazdır. Çamlıbel diyabazları incelendiğinde; olivin miktarının \%2'den az olduğu, kuvars mineralinin olmadığ gözlenmiştir. $\mathrm{Bu}$ yüzden örneği piroksenli diyabaz sınıfında olduğu söylenebilir.

\subsection{Mekanik Özellikler}

Çalışma sahsından getirilen blok numuneler TSE 699'a uygun şekilde küp, karot ve prizma olarak hazırlanmıştır [9]. Hazırlanan örnekler üzerinde mekanik deneyler uygulanmıştır. Her bir deney için 5'er adet numune kullanılmış ve bulunan değerlerin ortalaması alınmıştır. Yapılan deneylerin sonuçları Çizelge 3 'de verilmiştir.

Çizelge 3. Çamlıbel diyabazı mekanik özellikleri

\begin{tabular}{|c|c|c|}
\hline Mekanik Özellikler & $\begin{array}{l}\text { Bulunan } \\
\text { Değer }\end{array}$ & $\begin{array}{c}\text { TS } 5762 \\
\text { Sınır Değer }\end{array}$ \\
\hline $\begin{array}{l}\text { Tek Eksenli Basınç } \\
\text { Dayanımı MPa }\end{array}$ & $179,82 \pm 0,1$ & $\begin{array}{l}\text { Kaplama } \\
\geq 117,68\end{array}$ \\
\hline $\begin{array}{l}\text { Eğilme Dayanımı } \\
(\mathrm{MPa})\end{array}$ & $42,14 \pm 0,5$ & Kaplama $\geq 7,36$ \\
\hline $\begin{array}{c}\text { Don Sonrası Eğilme } \\
\text { Dayanımı }(\mathrm{MPa})\end{array}$ & $40,19 \pm 0,6$ & \multirow[b]{2}{*}{ Kaplama $\leq 5$} \\
\hline $\begin{array}{c}\text { Don Sonrası Eğilme } \\
\text { Dayanımı Azalma } \\
(\%)\end{array}$ & $4,62 \pm 0,9$ & \\
\hline 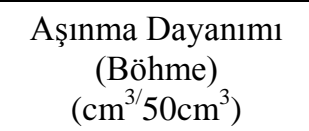 & $3,45 \pm 0,8$ & Kaplama $\leq 15$ \\
\hline
\end{tabular}


Numunenin sertlik sinıflaması Mohs sertlik sınıflamasına göre yapılmıştır. Örneğin Mohs sertliği 7,5 olarak belirlenmiştir.

Doğal taşlarda tek eksenli basınç dayanım değeri büyük önem taşımaktadır. TS 5762 [6]'e göre sınır değer 117,68 MPa'dır. İncelenen örneğin bulunan değeri bu değerden yüksektir [6].

Eğilme Dayanımı değerini incelediğimizde standartta verilen sınır değer 7,36 MPa'dır [6].

Diyabaz numunesinin don öncesi ve sonras eğilme dayanım değerleri sınır değerden yüksektir. Don sonrası eğilme dayanımında azalma ilgili standartta göre en fazla $\% 5$ olmalıdır. İncelenen örnek bu bakımdan sınır değerin altındadır.

Böhme aşınma dayanımı TS 5762 [6]'e göre kaplama taşı olarak kullanılacak ise en fazla $15 \mathrm{~cm}^{3} / 50 \mathrm{~cm}^{3}$, yapı yaşı olarak kullanılacak ise en fazla $10 \mathrm{~cm}^{3} / 50 \mathrm{~cm}^{3}$ olmalıdır. Diyabaz örneğimiz her iki şartı da sağlamaktadır.

\subsection{Kimyasal İçeriği}

Araziden getirilen parça örnek çeneli kırıcıda kırılarak öğütülmüş ve Panalytical marka X-Ray Fluoresence (XRF) cihazı kullanılarak numunenin kimyasal içeriğini belirlenmiştir. Analiz sonuçları Çizelge 4'de verilmiştir.

Çizelge 4. Çamlıbel diyabazının kimyasal içeriği

\begin{tabular}{|c|c|}
\hline İcerik & \% \\
\hline $\mathrm{SiO}_{2}$ & 52,11 \\
\hline $\mathrm{Al}_{2} \mathrm{O}_{3}$ & 15,16 \\
\hline $\mathrm{Fe}_{2} \mathrm{O}_{3}$ & 12,28 \\
\hline $\mathrm{CaO}$ & 6,88 \\
\hline $\mathrm{Na}_{2} \mathrm{O}$ & 6,38 \\
\hline $\mathrm{MgO}$ & 4,41 \\
\hline $\mathrm{TiO}_{2}$ & 1,16 \\
\hline $\mathrm{P}_{2} \mathrm{O}_{5}$ & 0,78 \\
\hline $\mathrm{K}_{2} \mathrm{O}$ & 0,49 \\
\hline $\mathrm{MnO}$ & 0,21 \\
\hline $\mathrm{Diğer}$ & 0,14 \\
\hline
\end{tabular}

\section{SONUÇLAR}

Yapılan bu çalışma ile Çamlıbel (Tokat) diyabazlarının bazı fiziko-mekanik özellikleri belirlenmiş ve bu özellikler TS 5762 [6] ile karşılaştırılmıştır. Bütün bunların yanı sıra doğal taşların kullanımında önemli bir yer tutan kimyasal içerik ile petrografik ve minerolojik özellikler de belirlenmiştir.

Çamlıbel (Tokat) diyabazının mekanik ve fiziksel özellikleri değerlendirildiğinde TS 5762'de [6] verilen standart değerlere uygun olduğu görülmüştür. Özellikle tek eksenli basınç dayanımı, aşınma dayanımı, eğilme ve son sonrası eğilme dayanımlarının oldukça yüksek olduğu görülmektedir. $\mathrm{Bu}$ sonuçlar Çamlıbel (Tokat) diyabazının yüksek dayanıma sahip olduğunu, yapı ve kaplama taşı olarak kullanımının uygun olduğunu göstermektedir. Kimyasal analiz, mineralojik ve petrografik analiz sonuçları da fizoko-mekanik analiz sonuçlarını destekleyici yönde çıkmıştır.

\section{TEŞEKKÜR}

Petrografik ve mineralojik analizlerin yapılmasına yardımcı olan Sayın Yrd. Doç. Dr. Nil YAPICI' ya teşekkür ederiz.

\section{KAYNAKLAR}

1. www.ntso.org.tr/upload/dosya/dosya/3bfbee $2 a$ de33cb40ce3b9bc8c280a8f7.pdf, Erişim Tarihi: 13.06.2016.

2. Tutuş, M., 2007. Çukurova Yöresinde Bulunan Bazı Mermerlere ait Fizikomekanik Özelliklerin İstatistiksel Analizi, Çukurova Üniversitesi Fen Bilimleri Enstitüsü Yüksek Lisans Tezi, Adana.

3. http://diyabaz.ticiz.com/product_list/group_154 999, Erişim Tarihi: 13.06.2016.

4. Tatar, Y., 1971. Ofiyolitli Çamlıbel (Yıldızeli) Bölgesinin Stratigrafi ve Petrografisi, MTA Dergisi, 88, 56-72, Ankara.

5. TS EN 1469, 2006. Doğal Taş MamulleriKaplamada Kullanılan Plakalar-Özellikleri, TSE, Ankara. 
6. TS 5762, 2004. Diyabaz-Yap1 ve Kaplama Taşı Olarak Kullanılan, TSE, Ankara.

7. Gündüz, L., Uğur, İ, Demirdağ, S., 2001. Mermer Türlerinin Özgül Isı Kapasitesi Değerleri Üzerine Teknik Bir İnceleme, Türkiye 3. Mermer Sempozyumu Bildiriler Kitab1, 181-196, Afyon.

8. Tarhan, F., 1989. Mühendislik Jeolojisi Prensipleri, K.T.Ü. Basımevi, Trabzon.

9. TS 699, 2009. Doğal Yapı Taşları İnceleme ve Laboratuvar Deney Yöntemleri, TSE, Ankara.

10. Güneri, S., 2009. Doğal Taşların Teknik Özelliklerine Göre Kullanım Alanlarının ve Uygulama Parametrelerinin Belirlenmesi, Dokuz Eylül Üniversitesi Fen Bilimleri Enstitüsü Yüksek Lisans Tezi, İzmir. 